\title{
IMOBILIZAÇÃO DE LIPASE DE Burkholderia cepacia EM SÍLICA MESOPOROSA MODIFICADA COM LÍQUIDO IÔNICO PRÓTICO PARA SÍNTESE DE ÉSTERES ETÍLICOS
}

\author{
N. B. CARVALHO ${ }^{1}$, B. T. VIDAL ${ }^{1}$, A. C. PROFESSOR ${ }^{1}$, A. S. BARBOSA ${ }^{1}$, M. M. \\ PEREIRA $^{2}$, L. S. FREITAS ${ }^{3}$, A. T. FRICKS ${ }^{1}$, S. MATTEDI ${ }^{4}$ A. S. LIMA ${ }^{1}$ e C. M. F. \\ SOARES ${ }^{1}$ \\ ${ }^{1}$ Universidade Tiradentes, Instituto de Tecnologia e Pesquisa \\ ${ }^{2}$ Universidade de Aveiro, Departamento de Química \\ ${ }^{3}$ Universidade Federal de Sergipe, Departamento de Química \\ ${ }^{4}$ Universidade Federal da Bahia, Departamento de Engenharia Química \\ E-mail para contato: nayara.eng@ @otmail.com
}

\begin{abstract}
RESUMO - O objetivo deste trabalho foi sintetizar ésteres etílicos utilizando lipase de Burkholderia cepacia imobilizada por adsorção física em sílica mesoporosa produzida na presença do líquido iônico prótico - LI (pentanoato de $\mathrm{N}$-metilmonoetalonamina). As reações de transesterificação foram conduzidas utilizando etanol e óleo de soja ou canola $(7: 1), 20 \%(\mathrm{~m} / \mathrm{m})$ de biocatalisador à $40^{\circ} \mathrm{C}$ e $80 \mathrm{rpm}$ durante $120 \mathrm{~h}$. Os ésteres foram analisados por cromatografia à gás. O valor máximo de conversão utilizando biocatalisadores produzidos na ausência de LI foi de 73\% (120h) para o óleo de soja e 68\% (96h) para o óleo de canola. Contudo, a utilização do LI no preparo do biocatalisador propiciou o aumento de conversão para $83 \%$ em $96 \mathrm{~h}$ para ambos os óleos. Os suportes de sílica mesoporosa e os biocatalisadores foram caracterizados pelos métodos de B.E.T. identificando modificações na superfície da sílica e espectroscopia de infravermelho (FTIR) confirmando a imobilização da enzima. Portanto, a lipase imobilizada em sílica produzida com líquido iônico apresenta potencial para a produção de ésteres.
\end{abstract}

\section{INTRODUÇÃO}

A imobilização de lipase é um método amplamente aplicado na biocatálise com o objetivo de melhoria na estabilidade e eficiência desta enzima. No entanto, as características dos suportes influenciam significantemente nas propriedades da enzima imobilizada (Gerardin et al., 2014; Zhou e Hartmann, 2013). Dentre os suportes, a sílica é uma promissora matriz hidrofóbica devido à sua estabilidade química, grande área de superfície, tamanho de poro controlado e presença de grupos silanóis na superfície, os quais estão disponíveis para imobilização da lipase pelo processo de adsorção física (Kapoor e Gupta 2012; Talbert e Goddar, 2012).

A modificação da superfície de suportes de sílica com aditivos pode ser realizada para melhorar as propriedades do suporte e consequentemente da enzima imobilizada (Hu et al 2012). Segundo Karout e Pierre (2007), a presença de líquido iônico como aditivo podem 
influenciar a estrutura do gel e o tamanho dos poros do suporte de sílica obtido pela técnica sol-gel, conforme descrito por Souza et al. (2013) e Zarcula et al. (2010). Contudo, poucos estudos têm relatado a produção de suporte de sílica com líquido iónico aplicados posteriormente à imobilização de enzima, necessitando então de estudos complementares como ponto de partida do desenvolvimento de um método de imobilização de enzimas em suportes modificados e aplicação do biocatalsiador em reações de síntese de ésteres (Andrade et al., 2012; Hu et al 2012).

Embora a função natural da lipase seja de quebrar as ligações de éster de triacilgliceróis com o consumo de moléculas de água (hidrólise), as lipases são também capazes de catalisar a reação reversa sob condições micro-aquosa, como por exemplo, a formação de ésteres etílicos a partir de álcool etílico e óleo vegetal. As lipases imobilizadas, quando aplicadas em reação de transesterificação, torna o processo ambientalmente correto devido à baixa energia envolvida, não formação de reações secundárias, baixa toxicidade, e principalmente fácil separação do produto e do biocatalisador, possivelmente em reações contínuas ou repetidamente (Borugadda e Goud., 2012; Tan et al., 2010).

Neste contexto, o presente trabalho tem como objetivo sintetizar ésteres etílicos a partir do óleo de soja ou canola e o álcool aceptor foram o etanol, utilizando lipase de Burkholderia cepacia imobilizada por adsorção física em sílica mesoporosa produzida na presença do líquido iônico prótico (pentanoato de $\mathrm{N}$-metilmonoetalonamina). Para a confirmar as modificações na superfície da sílica e as características físico-químicas do suporte e dos biocatalisadores imobilizados foram realizadas análises pelos métodos de B.E.T. e espectroscopia de infravermelho (FTIR).

\section{METODOLOGIA}

\subsection{Materiais}

A lipase de Burkholderia cepacia $\left(\geq 30,000 \mathrm{U} / \mathrm{g}\right.$ à $\mathrm{pH} 7.0$ e $\left.50^{\circ} \mathrm{C}\right)$, e o precursor de sílica foi o tetraetilortosilicato (TEOS), foram adquiridos da Sigma-Aldrich. O líquido iônico prótico (pentanoato de N-Metilmonoetanolamina) foi fornecido pela Universidade Federal da Bahia (UFBA). Todos os outros reagentes utilizados foram de grau analítico.

\subsection{Produção de Sílica Mesoporoso e Imobilização por Adsorção Física}

A técnica sol-gel foi realizada para a produção de sílica mesoporosa conforme Souza et al. (2013) com algumas modificações: adicionou-se 1\% (v/v) de líquido iônico prótico (pentanoato de N-Metilmonoetanolamina) durante a síntese da sílica mesoporosa (sílica com líquido iônico, SLI) e o controle foi preparado sem líquido iônico (sílica pura , SP). O procedimento de adsorção física (ADS) para imobilização da lipase de Burkholderia cepacia foi realizado conforme Soares et al. 2004 a partir do contato da solução enzimática aquosa com a sílica mesoporosa obtida pela técnica sol-gel (razão mássica lipase : sílica mesoporosa de $0,3: 1)$, em meio orgânico $(3 \mathrm{~h}, 50 \mathrm{rpm})$, seguido de repouso $\left(4^{\circ} \mathrm{C}\right.$ por $\left.24 \mathrm{~h}\right)$, lavagem, filtragem e secagem. 


\subsection{Rendimento de Imobilização}

O rendimento de imobilização (RI) foi determinado por meio da reação de padrão para lipase, a hidrólise do azeite de oliva. A atividade hidrolítica foi determinada pelo método descrito por Soares et al. (1999) e substrato foi composto pelo óleo de oliva emulsionado com água destilada e goma arábica. Os ácidos graxos liberados foram titulados com solução padronizada de $\mathrm{KOH}$, utilizando fenolftaleína como indicador. Uma unidade de atividade é definida como a quantidade de enzima que libera em $1 \mu \mathrm{mol}$ de ácido graxo por min de reação, nas condições do ensaio. As atividades foram expressas em (1U/g=1 $\mu$ moles/g.min) como pode ser vista na Equação 1.

$$
\text { Atividade enzimática }(U / g)=\frac{\left(V_{a}-V_{b}\right) \times N \times 1000}{t \times m}
$$

onde $\mathrm{V}_{\mathrm{a}}$ é o volume da amostra titulada $(\mathrm{mL}), \mathrm{V}_{\mathrm{b}}$ é o volume do branco titulado $(\mathrm{mL}), \mathrm{m}$ é a massa da amostra utilizada na reação $(\mathrm{g}), \mathrm{N}$ é a molaridade da solução de $\mathrm{KOH}(\mathrm{mol} / \mathrm{L})$ e t é o tempo de reação em minutos.

O rendimento de imobilização foi calculado conforme Equação 2:

$$
R I(\%)=\frac{U_{S}}{U_{0}} \times 100
$$

onde $\mathrm{U}_{\mathrm{S}}$ é a unidade de atividade enzimática total presente no suporte de sílica mesoporosa e $\mathrm{U}_{0}$ é a unidade de atividade oferecida para imobilização.

\subsection{Atividade de Transesterificação}

As reações de síntese de ésteres etílicos foram realizadas em frascos com tampas autoclaváveis hermeticamente fechados, utilizando agitador orbital (80 rpm) conforme Freitas et al. (2009). Os experimentos foram conduzidas por $120 \mathrm{~h}$, utilizando diferentes óleos (soja ou canola) e etanol na razão molar 1:7 (óleo:álcool), temperatura $\left(40^{\circ} \mathrm{C}\right)$ e $20 \%(\mathrm{~m} / \mathrm{m})$ dos biocatalisadores imobilizados. Após a purificação, os ésteres foram analisados por cromatógrafo à gás (Shimadzu - 2010) com detector de ionização de chama FID e coluna CARBOVAX $(30 \mathrm{~m} \times 0.25 \mathrm{~mm} \times 0.25 \mathrm{~mm})$. A temperatura da coluna foi inicialmente mantida a $170^{\circ} \mathrm{C}$ durante $1 \mathrm{~min}$, crescente para $210^{\circ} \mathrm{C}$ a uma taxa de $10^{\circ} \mathrm{C} / \mathrm{min}$, mantida durante $1 \mathrm{~min}$, alcançando $230^{\circ} \mathrm{C}$, mantido durante mais $5 \mathrm{~min}$. As temperaturas do injetor e do detector foram ajustadas para $250^{\circ} \mathrm{C}$. 
A conversão em ésteres de etila foi quantificada conforme Equação 3 abaixo:

$$
\text { Conversão }(\%)=\frac{(A T-P I)}{P I} \times \frac{(C P I \times 100)}{C E}
$$

onde: AT: área total dos picos; PI: área do padrão interno; CPI: concentração do padrão interno; CE: concentração enzimática.

\subsection{Caracterização da Sílica Mesoporosa e dos Biocatalisadores Imobilizados}

Os suportes de sílica mesoporosa e os biocatalisadores imobilizados foram caracterizados pelos métodos de B.E.T. e espectroscopia de infravermelho com transformada de Fourier (FTIR). A medição da área superficial e as isotermas foram realizadas por adsorção, utilizando nitrogênio como absorbato. As amostras foram previamente tratadas a $300^{\circ} \mathrm{C}$ por $3 \mathrm{~h}$, $\log$ o após foram desgaseificadas abaixo de $50 \mathrm{mmHg}$. Os parâmetros de área superficial $\left(\mathrm{m}^{2} / \mathrm{g}\right)$, diâmetro do poro $(\AA)$ e volume do poro $\left(\mathrm{cm}^{3} / \mathrm{g}\right)$ foram calculados usando o método Brunauer-Emmett-Teller (B.E.T). A determinação da estrutura química superficial das partículas foi investigada através de ensaios de infravermelho (espectrômetro FTIR de refletância total atenuada, Perkin Elmer). Os espectros foram coletados na faixa de 4000-500 $\mathrm{cm}^{-1}$.

\section{RESULTADOS E DISCUSSÕES}

\subsection{Rendimento de Imobilização}

Os suportes de sílica mesoporosa produzidos com líquido iônico (SLI) e a sílica controle produzida sem líquido iônico (SP) foram utilizados para imobilização da lipase de Burkholderia cepacia pela técnica de adsorção física e posterior análise do rendimento de imobilização por meio da reação de hidrólise do azeite de oliva. Os resultados mostram que a influência do líquido iônico para a produção da sílica mesoporosa foi positiva para a imobilização da lipase passando de 39 para $71 \%$ de rendimento de imobilização. Esta diferença é devida possivelmente à uma forte adsorção hidrofóbica da enzima na superfície e nos poros do suporte de sílica mesoporosa produzida com líquido iônico.

Zou et al. (2010) utilizaram o líquido iônico aprótico baseados em imidazol, 1-Metil-3(3-trimetoxissilil-propil) imidazólio tetrafluoroborato, para modificação superficial da sílica mesoporosa, SBA-15. A lipase de pâncreas de suíno foi imobilizada por adsorção física e os resultados deste estudo demonstraram que o rendimento de imobilização na produção do emulsificante triacetina foi de 53\%. A diferença do rendimento de imobilização deve-se possivelmente ao sítio ativo hidrofóbico da lipases adsorvidas nas superfícies de sílica mesoporosa e consequentemente a sua conformação e estabilização quando em contato com substratos pequenos e hidrofóbicos. Portanto, pode-se observar que no presente estudo a lipase imobilizada em sílica mesoporosa produzidas na presença de LI apresentou melhores rendimentos de imobilização comparado com a literatura (Fernandez-Lafuente et al, 1998; Reetz, 1997). 


\subsection{Síntese de Ésteres Etílicos}

Os resultados obtidos no presente trabalho e apresentados na Figura 1 mostram que os ésteres etílicos alcançaram máxima conversão utilizando biocatalisadores imobilizados produzidos na ausência de LIP de 73\% (120h) para o óleo de soja e 68\% (96h) para o óleo de canola. E com a utilização do LIP no preparo do biocatalisador propiciou o aumento de conversão para $83 \%$ em $96 \mathrm{~h}$ para ambos os óleos. Estes resultados são promissores, pois a transesterificação de óleos na presença do álcool etílico e lipase como biocatalisador é considerada uma rota "mais verde" (Tan et al., 2010). Contudo, vale ressaltar que no presente estudo foi utilizado reator convencional e, portanto estes resultados de produção de ésteres confirmam a importância do aprimoramento da imobilização de lipases em sílica mesoporosa com alcance de altas conversões e possibilidade de otimização, assim como a introdução de aditivos no meio reacional, variação da razão molar, temperatura e cinética reacional, buscando-se alcançar $100 \%$ de conversão de ésteres etílicos.

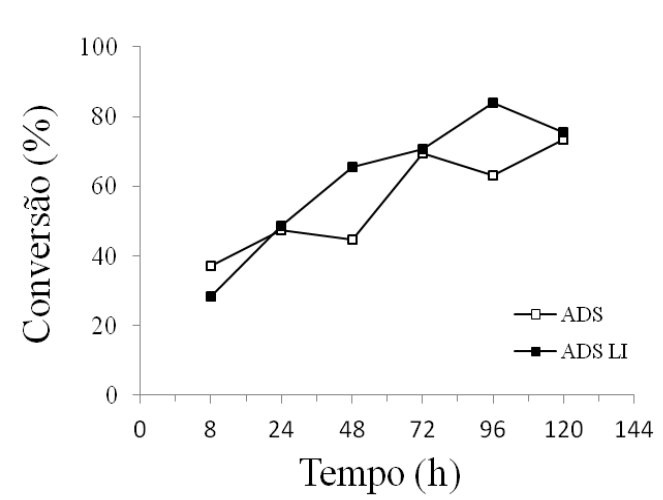

(a)

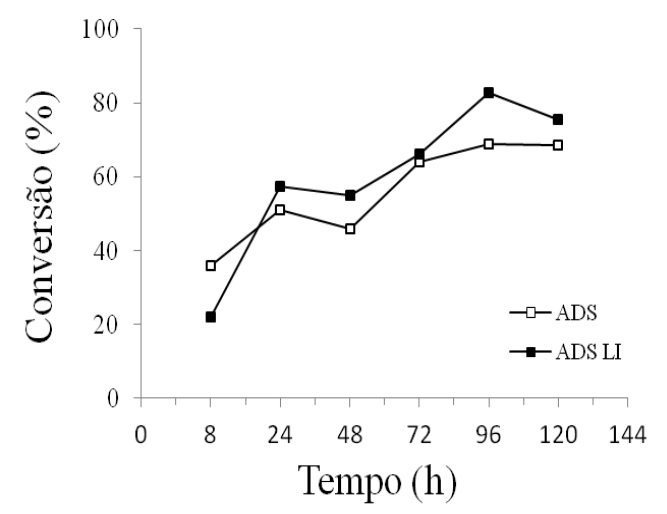

(b)

Figura 1 - Conversão em ésteres etílicos do óleo de soja (a) ou canola (b) na presença do biocatalisador imobilizado por adsorção física (ADS) em suporte de sílica mesoporosa.

\subsection{Caracterização da Sílica Mesoporosa e dos Biocatalisadores Imobilizados}

A determinação da área superficial específica, volume e diâmetro de poros foram baseados no volume de nitrogênio gasoso adsorvido em várias pressões a $77 \mathrm{~K}$. Os resultados mostrados na Tabela 1 indicam um aumento significativo na área de superfície após a adição do líquido iônico na síntese da sílica mesoporosa, a área superficial de 799,5 m²/g (SP) foi para $853,5 \mathrm{~m}^{2} / \mathrm{g}$ (SLI). Observou-se o mesmo comportamento para os volumes dos poros $\left(0,57 \mathrm{~cm}^{3} / \mathrm{g}\right.$ para $\left.1,02 \mathrm{~cm}^{3} / \mathrm{g}\right)$ e diâmetro dos poros $(3,02$ para 3,82nm) após a adição do LI na síntese da sílica mesoporosa. No estudo realizado por Hu et al. (2012), obteve um efeito oposto depois do tratamento de sílica mesoporosa modificado por líquido iônico imidazol para a imobilização da lipase de Burkholderia cepacia. Desta forma, podemos concluir que as características do líquido iônico como tipo de grupo funcional utilizado pode influenciar no efeito causado à superfície do suporte devido à extensibilidades diferentes, flexibilidade e conformação espacial (Zarcula et al.,2010; Alvarez et al., 2010). 
Após imobilização da lipase observou-se o decréscimo na área da superfície da sílica mesoporosa quando comparado ao controle (sílica pura sem líquido iônico, SP), devido possivelmente a presença da lipase imobilizada na superfície e poros do suporte de sílica, impedindo o acesso de moléculas de nitrogênio gasoso. A área superficial da partícula, volume e diâmetro poros apresentaram maiores valores quando a lipase foi imobilizada em suportes produzidos na presença de LI quando comparado ao controle (sílica mesoporosa na ausência de LI), perfil também apresentado na análise dos suportes de sílica (Tabela 1).

Tabela 1 - Área superficial e volume dos poros dos suportes de sílica produzidos pela técnica sol gel na ausência (SP) ou presença (SLI) de líquido iônico.

\begin{tabular}{|c|c|c|c|}
\hline Amostras & $\begin{array}{c}\text { Área Superficial } \\
\left(\mathbf{m}^{\mathbf{2}} / \mathbf{g}^{-\mathbf{1}}\right)\end{array}$ & $\begin{array}{c}\text { Volume dos Poros } \\
\left(\mathbf{c m}^{\mathbf{3}} / \mathbf{g}^{-\mathbf{1}}\right)\end{array}$ & $\begin{array}{c}\text { Diâmetro dos Poros } \\
(\mathbf{n m})\end{array}$ \\
\hline SP & 799,5 & 0,57 & 3,02 \\
\hline SLI & 853,5 & 1,02 & 4,17 \\
\hline ADS-SP & 579,9 & 0,64 & 3,82 \\
\hline ADS-SLI & 706,8 & 0,87 & 4,22 \\
\hline
\end{tabular}

A composição química superficial dos suportes de sílica mesoporosa e dos biocatalisadores imobilizados foi analisada por Espectroscopia na Região do Infravermelho com Transformada de Fourrier (FTIR) e observou-se bandas características de grupamentos presentes nos suportes: Si-O-Si a 620 e $1000 \mathrm{~cm}^{-1}$, Si-O-H a $1100-900 \mathrm{~cm}^{-1}$ (Souza et al, 2013; Andrade et al, 2010; Soares et al, 2004) (Figura 2). Estas absorções características indicam a formação das ligações entre a sílica como uma polimerização do alcooxido TEOS, durante a formação da matriz/suporte de sílica mesoporosa (Anuar et al., 2013).

Para avaliação da eficiência da imobilização da lipase no suporte produzido na presença de LI os espectros de FTIR dos suportes de sílica mesoporosa, na ausência ou presença de LI, bem como da lipase de Burkholderia cepacia livre (LBC) e suas formas imobilizadas foram sobrepostas na Figura 2 para avaliação das bandas características. A lipase apresenta um espectro típico de proteínas com as bandas associadas à sua característica de amida (grupo IV e V), na gama de $695 \mathrm{~cm}^{-1}$, e compostos da lipase (C-C e C-N) também pode ser observado entre $1100-1000 \mathrm{~cm}^{-1}$ de acordo com Portaccio et al., (2011) e por Andrade et al., (2010). As bandas que representam amidas IV e V também estão presentes no espectro de ADS-SP e ADS-SLI, revelando assim a presença de LBC em sistemas imobilizados. No entanto, a posição de amida é sensível ao ambiente em torno da proteína e seu deslocamento para números de onda mais baixos parece refletir a imobilização e possíveis alterações estruturais. Por conseguinte, as alterações observadas nos espectros vibracionais corroboram com a influência do suporte na imobilização da enzima e no aumento do rendimento de imobilização conforme mencionado anteriormente (39\% para a ADS-SP para $71 \%$ para a ADS-SLI). Ressalta-se também a presença nos biocatalisadores imobilizados de grupamentos do suportes já citados no FTIR dos suportes: Si-O-Si a 800, 620 e $1000 \mathrm{~cm}^{-1}$, Si-O-H a 1100$900 \mathrm{~cm}^{-1}$ (Souza et al., 2013; Andrade et al., 2010; Soares et al., 2004). 


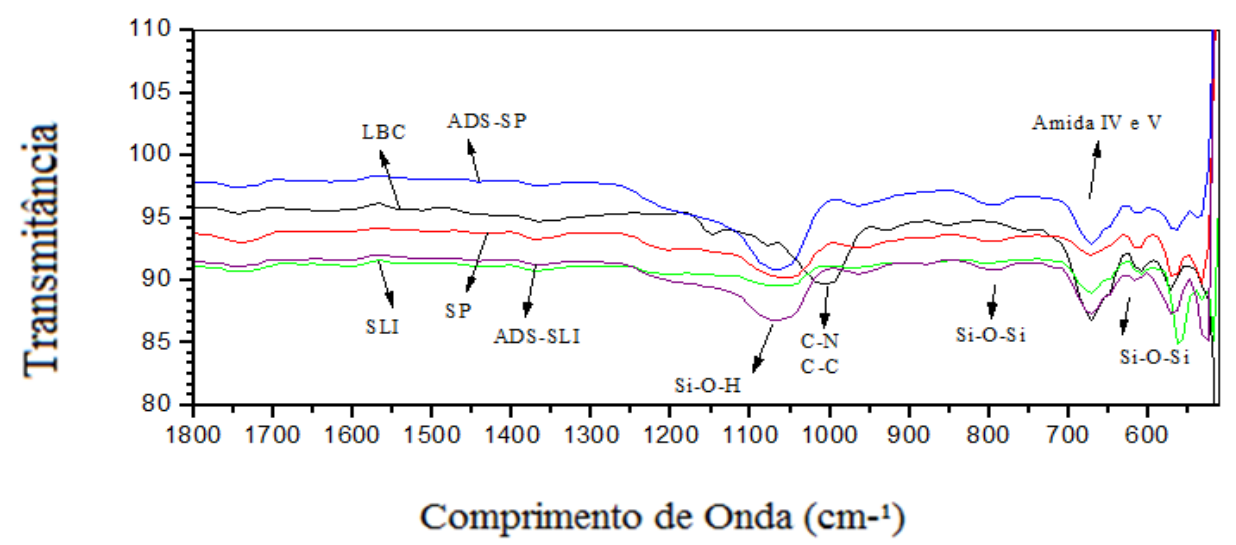

Figura 2 - Espectrograma FTIR da LBC, dos suportes de sílica mesoporosa produzida pela técnica sol-gel na ausência (SP) ou presença (SLI) de líquido iônico e dos biocatalisadores imobilizados por adsorção física (ADS).

\section{CONCLUSÃO}

A modificação da sílica mesoporosa pelo líquido iônico promoveu o aumento da área superficial, do volume e do diâmetro dos poros. O FTIR confirmou a presença da lipase imobilizada na sílica mesoporosa a partir da identificação dos grupamentos amida. Confirmada pela determinação do rendimento de imobilização na reação de hidrólise do azeite de oliva na qual a sílica mesoporosa produzida com líquido iônico foi mais eficiente, passando de 39 para $71 \%$ no rendimento de imobilização. Na síntese de ésteres etílicos a partir da reação de transesterificação do etanol com o óleo de soja ou canola, o valor máximo de conversão utilizando biocatalisadores produzidos na ausência de LI foi de 73\% (120h) para o óleo de soja e 68\% (96h) para o óleo de canola. Enquanto que, a utilização do LI no preparo da sílica mesoporosa para imobilização da lipase verificou-se o aumento de conversão para $83 \%$ em 96h para ambos os óleos. Portanto, podemos concluir que o líquido iônico proporcionou uma melhoria no sistema imobilizado e maior eficiência quando aplicados na reação de hidrólise e transesterificação.

\section{REFERENCIAS}

ALVAREZ, V. H.; MATTEDI, S.; MARTIN-PASTOR, M.; AZNAR, M.; IGLESIAS, M. Synthesis and thermophysical properties of two new protic long-chain ionic liquids with the oleate anion. Fluid Phase Equilib., v. 299, p. 42-50, 2010.

ANDRADE, G. S. S.; FREITAS, L.; OLIVEIRA, P. C.; CASTRO, HEIZIR F. Screening, immobilization and utilization of whole cell biocatalysts to mediate the ethanolysis of babassu oil. J. Mol. Catal. B: Enzym., v. 84, p. 183-188, 2012.

ANUAR, S. T.; ZHAO, Y.; MOGO, S. M.; CURTIS, J. M. The development of a capillary microreactor for transesterification reactions using lipase immobilized onto a silica monolith. J. Mol. Catal. B: Enzym., v.92, p. 62- 70, 2013.

BORUGADDA, B.; GOUD, V. V. Biodiesel production from renewable feed stocks: Status and opportunities. Renew. Sust. Energ. Rev., v. 16, p.4763-4784, 2012. 
FERNANDEZ-LAFUENTE, R.; ARMISEN, P.; SABUQUILLO, P.; FERNANDEZLORENTE, G.; GUISAN, J. M. Immobilization of lipases by selective adsorption on hydrophobic supports. Chem. Phys. Lipids., v. 93, p. 185-197, 1998.

FREITAS, L.; DA RÓS, P. C. M.; SANTOS, J. C.; DE CASTRO, H. F. An integrated approach to produce biodiesel and monoglycerides by enzymatic interestification of babassu oil (Orbinya sp). Process Biochem., v. 44, p. 1068-1074, 2009.

GERARDIN, C.; REBOUL, J; BONNE, M.; LEBEAU, B. Ecodesign of ordered mesoporous silica materials. Chem. Soc. Rev., v. 42, p. 4217-4255, 2013.

HU, Y.; TANG, S.; JIANG, L.; ZOU, B.; YANG, J.; HUANG, H. Immobilization of Burkholderia cepacia lipase on functionalized ionic liquids modified mesoporous silica SBA15. Process Biochem., v. 47, p. 2291-2299, 2012.

KAPOOR, M.; GUPTA, M. N. Lipase promiscuity and its biochemical applications. Process Biochem., v. 47, p. 555-569, 2012.

KAROUT, A.; Pierre, A. C. Silica xerogels and aerogels synthesized with ionic liquids. $J$. Non-Cryst Solids, v. 353, p. 2900-2909, 2007.

PORTACCIO, M.; VENTURA, B. D.; MITA, D. G.; MANOLOVA, N.; STOILOVA, O.; RASHKOV, I.; LEPORE, M. FT-IR microscopy characterization of sol-gel layers prior and after glucose oxidase immobilization for biosensing applications. J. Sol-Gel Sci. Techn., v. 57, p. 204-211, 2011.

REETZ, M. T. Entrapment of biocatalysts in hydrophobic sol-gel materials for use in organic chemistry. Adv. Mater, v. 9, p. 943, 1997.

SOARES, C. M. F.; CASTRO, H. F.; MORAES, F. F.; ZANIN, G. M. Characterization and utilization of Candida rugosa lipase immobilized on controlled pore silica. Appl. Biochem. Biotechnol., v. 77, p. 745-758, 1999.

SOARES, C. M. F.; SANTOS O. A., CASTRO, H. F.; MORAES, F. F. ; ZANIN, G. M. Studies on lipase immobilization in hydrophobic sol-gel matrix. Appl. Biochem. Biotechnol., v. 113, p. 307-319, 2004.

SOUZA, R. L.; FARIA, E. P.; CONCEIÇÃO, T. G. C.; CARVALHO, N. B.; FRICKS, A. T.; FIGUEIREDO, R. T.; CASTRO, H. F.; ZANIN, G. M.; SANTOS, O. A.; FREITAS, L. S.; SILVA, S. M.; DURO, M. A. I.; COUTINHO, J. A. P.; LIMA, A. S.; SOARES, C. M. F. Production of ethyl esters and emulsifiers using immobilized Burkholderia cepacia lipase with protic ionic liquid as additives. Enzyme Microb. Technol., v. 52, p. 141-50, 2013.

TALBERT, J. N.; GODDARD, J. M. Enzymes on material surfaces. Colloids Surf., B., v. 93, p. 8- 19, 2012.

TAN, T.; LU, J.; NIE, K.; DENG, L.; WANG, F. Biodiesel production with immobilized lipase: A review. Biotechnol. Adv., v. 28, p. 628-634, 2010.

ZARCUlA, C.; CORÎCI, L.; CROITORU, R.; URSOIU, A.; PETER, F. Preparation and properties of xerogels obtained by ionic liquid incorporationduring the immobilization of lipase by the sol-gel method. J. Mol. Catal. B: Enzym., v. 65, p. 79-86, 2010.

ZHOU, Z.; HARTMANN, M. Progress in enzyme immobilization in ordered mesoporous materials and related applications. Chem. Soc. Rev., v. 42, p. 3894-392. 